\title{
Effect of hyperextension of the neck (rose position) on cerebral blood oxygenation in patients who underwent cleft palate reconstructive surgery: prospective cohort study using near-infrared spectroscopy
}

\author{
B.J.A. Smarius ${ }^{1}$ - C.C. Breugem ${ }^{2,3}$ - M.P. Boasson ${ }^{4}$ - S. Alikhil ${ }^{4}$ • J. van Norden ${ }^{4}$ - A.B. Mink van der Molen ${ }^{1}$. \\ J.C. de Graaff ${ }^{4,5}$
}

Received: 26 March 2019 / Accepted: 13 November 2019 / Published online: 26 March 2020

(C) The Author(s) 2019

\begin{abstract}
Objectives To facilitate the best approach during cleft palate surgery, children are positioned with hyperextension of the neck. Extensive head extension may induce intraoperative cerebral ischemia if collateral flow is insufficient. To evaluate and monitor the effect of cerebral blood flow on cerebral tissue oxygenation, near-infrared spectroscopy has proved to be a valuable method. The aim of this study was to evaluate and quantify whether hyperextension affects the cerebral tissue oxygenation in children during cleft palate surgery.

Materials and methods This prospective study included children (ASA 1 and 2) under the age of 3 years old who underwent cleft palate repair at the Wilhelmina Children's Hospital, in The Netherlands. Data were collected for date of birth, cleft type, date of cleft repair, and physiological parameters (MAP, saturation, heart rate, expiratory $\mathrm{CO}_{2}$ and $\mathrm{O}_{2}$, temperature, and cerebral blood oxygenation) during surgery. The cerebral blood oxygenation was measured with NIRS.

Results Thirty-four children were included in this study. The majority of the population was male $(61.8 \%, n=21)$. The mixed model analyses showed a significant drop at time of Rose position of -4.25 (69-74 95\% CI; $p<0.001)$ and $-4.39(69-7495 \%$ CI; $p<0.001$ ). Postoperatively, none of the children displayed any neurological disturbance.

Conclusion This study suggests that hyperextension of the head during cleft palate surgery leads to a significant decrease in cerebral oxygenation. Severe cerebral desaturation events during surgery were uncommon and do not seem to be of clinical relevance in ASA 1 and 2 children.

Clinical relevance There was a significant drop in cerebral oxygenation after positioning however it is not clear whether this drop is truly significant physiologically in ASA 1 and 2 patients.
\end{abstract}

B.J.A. Smarius

bja.smarius@umcutrecht.nl

J.C. de Graaff

j.degraaff@erasmusmc.nl

1 Department of Pediatric Plastic Surgery, Wilhelmina Children's Hospital, University Medical Center Utrecht, P.O. 85090, 3508 AB Utrecht, The Netherlands

2 Department of Pediatric Plastic Surgery, Emma Children's Hospital, University Medical Center Amsterdam,

Amsterdam, The Netherlands

3 Department of Plastic Surgery, Meander Medical Center, Amersfoort, The Netherlands

4 Department of Anesthesia, University Medical Center Utrecht, Utrecht, The Netherlands

5 Department of Anesthesia, Erasmus MC Sophia Children's Hospital, Rotterdam, The Netherlands
Keywords Cerebral blood oxygenation . Cleft palate . Near-infrared spectroscopy · NIRS · Rose position . Hyperextension

\section{Introduction}

Cleft palate is one of the most common disorders in newborn infants [1]. The incidence of cleft lip/palate in The Netherlands ranges from 1.4 to 2.1 per 1000 [2]. There is still no universally accepted treatment approach timing of cleft repair. Surgical repair of a cleft palate is preferably performed at young age to advance the development of normal speech, hearing, and feeding with minimal maxillary outgrowth restriction [3, 4]. During surgical cleft repair, the patients are positioned with 

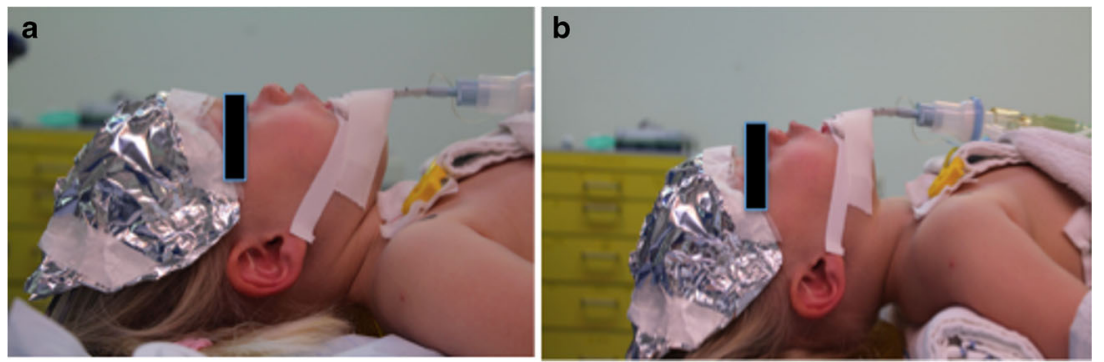

Fig. 1 a. The patient is supine positioned during baseline measurement and a photo is taken. b. Rose positioning: A towel is placed under the neck and proximal part of the shoulder. When head position adjustment has been applied a second photos is taken

hyperextension of the neck according to Rose position (Fig. 1). The Rose position is also often used for tonsillectomy, adenoidectomy, or uvulopalatopharyngoplasty to facilitate the best surgical approach [5].

Generally, sufficient cerebral blood supply is maintained by intra-cerebral collateral flow and cerebral blood flow is kept within normal range by autoregulation, even if the flow in one or more arteries is compromised. However, extensive head rotation or extension may induce intraoperative cerebral ischemia if the collateral flow is insufficient due to congenital abnormalities. Several studies have concluded that neck rotation and/or extension resulted in a change of blood flow in adults [6-8]. Also, venography in an infant cadaver showed that rotation of the neck leads to functional occlusion of the ipsilateral internal jugular vein due to twisting of the vessel on its axis [9, 10]. Theoretically, Rose position could lead to compression of the vein in the neck which in turn could further attenuate the cerebral blood flow and concomitant impairment of cerebral tissue oxygenation. Thus far, it is not known whether Rose position compromises cerebral blood flow and if it could consequently decrease the cerebral tissue oxygenation.

Impairment of cerebral blood flow could result in neurological damage (e.g., motor and cognitive impairments) since certain cerebral regions (gray matter nuclei, region between anterior and posterior cerebral arteries, region between middle and posterior arteries) are particularly vulnerable to a decrease in brain perfusion pressure [11].

To evaluate and monitor the effect of cerebral blood flow on cerebral tissue oxygenation, near-infrared spectroscopy (NIRS) has proved to be a valuable method [12]. Studies, where the de brain oxygenation was measured by using NIRS, have shown that body posture alteration (head elevation, prone, supine, and $90^{\circ}$-neck flexion during shoulder operations) in adults leads to a decrease in the mean arterial pressure (MAP) and cerebral perfusion of the brain [13-15].

To our knowledge, this is the first study examining the effect of Rose position on cerebral blood flow and cerebral tissue oxygenation in children. This study hypothesizes that the Rose position in supine positioned children affects the cerebral blood flow and concomitantly attenuates cerebral tissue oxygenation. Therefore, the present study aims to evaluate and quantify whether Rose position affects the cerebral tissue oxygenation in children who undergo cleft palate surgery. Our secondary objective was to evaluate whether cerebral tissue oxygenation reached below a critical limit during cleft palate surgery and if so, to observe possible concomitant brain tissue ischemia by means of neurological examination.

\section{Patient and methods}

\section{Clinical data}

Children under the age of 3 years old who underwent cleft palate repair at the Wilhelmina Children's Hospital, UMCU, in The Netherlands were included for this prospective study. All children were operated between May 2015 and May 2017. All children were operated by two experienced pediatric plastic surgeons, specialized in the treatment of cleft palate. Only children classified as ASA 1 or 2 and in which the anesthesia lasted longer than 30 min were included for the study.

Patients were excluded from the study if the application of NIRS probes would be impractical (e.g., surgery of head or neck combined with cleft palate surgery). Additionally, children were excluded if they had a medical history of neurological abnormalities, skull/scalp/frontal brain malformation, major cardiac deformations, or antihypertensive medication.

This study protocol did not bring any additional health risks. Permission for this study was obtained from the local Medical Ethical Board (number 15-254/C). Written informed consent was obtained from parents.

\section{Data collection}

Medical history, body weight at the time of surgery, and ASA classifications were obtained and the tissue brain oxygenation was collected from NIRS. In addition MAP, saturation, heart rate, expiratory $\mathrm{CO}_{2}$ and $\mathrm{O}_{2}\left(\right.$ etCO $\mathrm{O}_{2}$ and etO $\left.\mathrm{O}_{2}\right)$, and temperature were perioperatively collected by Anesthesia Information Management System (AIMS, Anstat, version 2.0.4, 2015, Carepoint, Ede, The Netherlands). MAP was measured every 
$5 \mathrm{~min}$, and all other physiological parameters every minute. In addition, the perioperative anesthetic, surgical complications, and perioperative drug administration were recorded in a case report form. To ensure that no important information was lost, the written information in the case report form was compared with the entries in AIMS. With Structured Query Language (SQL) (SQL Server 2014 Management Studio®), crude data was extracted from the hospital's database.

\section{Near-infrared spectroscopy (NIRS)}

The cerebral tissue oxygenation was measured at both lateral sides of the forehead with near-infrared spectroscopy (NIRS) by using NIRO-200 HX Hamamatsu® system, Tokyo, Japan [16]. This system measures cerebral oxyhemoglobin (O2HB) and deoxyhemoglobin $(\mathrm{HHb})$ concentrations by emitting infrared light. Based on $\mathrm{O} 2 \mathrm{HB}$ and $\mathrm{HHb}$, the regional cerebral tissue oxygenation index $(\mathrm{O} 2 \mathrm{HB} / \mathrm{O} 2 \mathrm{HB}+\mathrm{HHb} \cdot 100 \%)$ is calculated, which is an approximated equivalent of the cerebral blood oxygenation and is expressed as a percentage. Two optodes, containing light source and light detector, were set in a black holder before being applied on the forehead. Applying the optodes away from the midline and away from the lateral side of the frontal area was done to minimize/avoid the measurement of the superior sagittal sinus and the temporal muscles. Immediately after the induction of anesthesia and intubation, the probes were fixed on the supine-positioned child. Then, the forehead was fully covered by aluminum tin foil and pressure was applied to the tin foil to completely enclose the optodes. This was needed in order to minimize the signal to noise ratio, which is caused by environmental (sun) light.

\section{Anesthetic technique}

The patients were anesthetized according to the local anesthetic protocol in which all patients were anesthetized with $8 \%$ of the inhalation anesthetic sevoflurane in $100 \%$ oxygen followed by cefazolin $(50 \mathrm{mg} / \mathrm{kg})$ for surgical infection prophylaxis, sufentanil $(0.1-0.5 \mathrm{mcg} / \mathrm{kg})$ and atracurium $(0.5-0.75 \mathrm{mg} / \mathrm{kg})$ to facilitate oral intubation. Thereafter, $\mathrm{FiO}_{2}$ was lowered to $40 \%$ before starting measurements, and anesthesia was maintained using sevoflurane (ET 2.0$3.0 \%$ ). Furthermore, to mitigate the postoperative pain, a local analgesic $(\max 3 \mathrm{mg} / \mathrm{kg}$ bupivacaine $0.25 \%$ with $1: 200,000$ epinephrine) was inserted in the operative region by the surgeon to block the terminal branches of nasopalatine and greater palatine nerves. Before the end of surgery, a loading dose for postoperative pain was given according to local protocol (paracetamol 15-20 mg/kg, morphine $0.1 \mathrm{mg} / \mathrm{kg}$ ).

\section{Positioning and head-neck-angle measurement}

Rose position for surgery was applied by the surgeon by placing a rolled towel beneath the neck and/or proximal part of the shoulder (Fig. 1) [5]. To measure the head-neck-angle a photo was taken before and after positioning. The lens of the camera was focused on predefined landmarks (acromion, tragus, and canthus). To make the acromion clearly visible on the photo, the tip of acromion was palpated and marked with a black marker before taking a picture. A horizontal line was drawn through the acromion and an additional line was drawn between the acromion and tragus. From these two lines, the change in head/neck angle was calculated. Furthermore, a vertical line was drawn through the tragus and a second vertical line between the tragus and canthus (Fig. 2). From these two lines, the change in head tilt angle was calculated.

\section{Effect of head position on cerebral blood oxygenation}

The primary outcome of the study was to assess the influence of Rose position during cleft lip and/or cleft palate surgery on cerebral tissue oxygenation. Mean cerebral tissue oxygenation index (both left and right) over time were derived from the models for measurements between $3 \mathrm{~min}$ prior to Rose position and $10 \mathrm{~min}$ after Rose position. To assess the influence of the Rose position, measurements before Rose positioning (called "baseline measurement": mean of the 3 min before the Rose position) were compared with measurements after

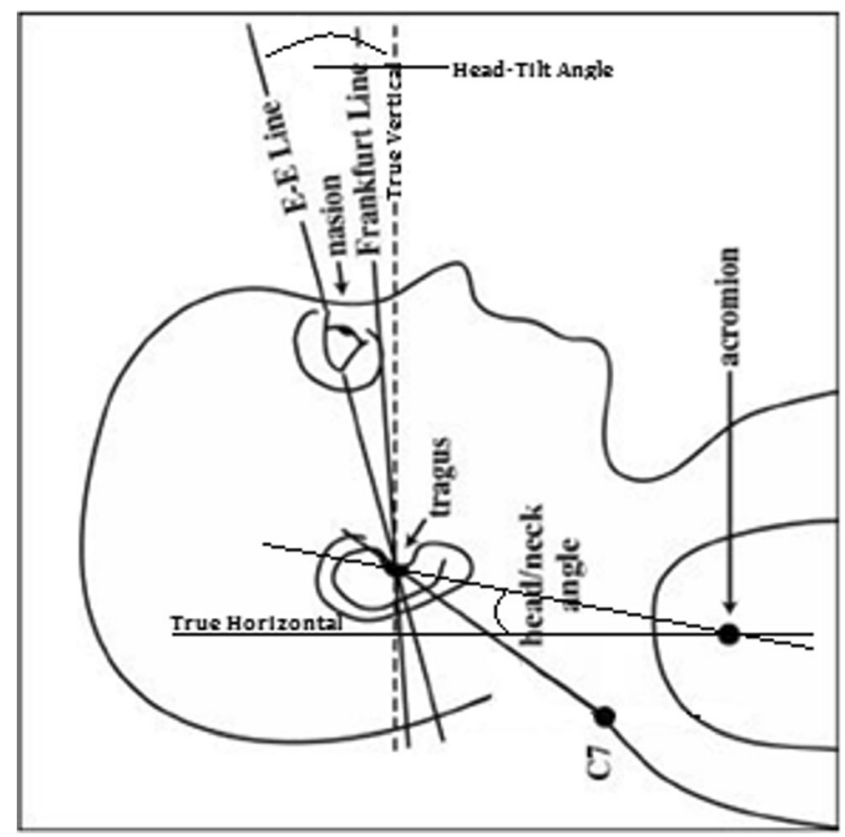

Fig. 2 A straight line (true horizontal line) was drawn through the acromion and an additional line was drawn between acromion and tragus. A straight vertical line was drawn through the tragus and a second line between the tragus and canthus. The same angles are measurement before and after head adjustment 
Rose positioning. Measurement started when et $\mathrm{O}_{2}$ was $<50 \%$ to ensure the true cerebral oxygenation.

There are no firmly established safety margins for cerebral tissue oxygenation index-values in humans. However, animal studies suggest that a threshold below $60 \%$ is associated with intermediate risk and below $45 \%$ high risk for damage [17, 18]. Therefore, we defined a cerebral tissue oxygenation index below $45 \%$ as severe low cerebral oxygenation.

\section{Operation technique}

All palate surgeries were performed by the standard treatment protocol at our department.

Children with an isolated cleft palate underwent cleft palate closure at 6-12 months. Children with unilateral/bilateral cleft lip palate underwent simultaneous cleft hard palate closure with a vomer flap and repair of cleft lip at the age of 36 months. Subsequently, the rest of the cleft palate was closed during a second intervention using a von Langenbeck technique preferably before the age of 12 months.

\section{Neurological assessment}

No standard neurological assessment was performed postoperatively. Neurological assessment by a neurologist was only performed on indication.

\section{Statistical analysis}

Demographic and other data recorded on the paper Case Report Form (CRF) were collated in IBM SPSS version 22 (SPSS Inc., Chicago, IL, USA) and analyzed with SAS v9.4 (SAS Institute Inc., Cary, NC). Descriptive summary statistics of baseline and intraoperative data were presented as frequencies and percentages for categorical variables and means and standard deviations for continuous variables after testing for skewness. Repeated measurements of saturation of the brain over time were analyzed with a linear mixed model for continuous outcomes. This approach was specifically chosen, since it does not require an equal number of measurements per patient and provides optimal statistical power for the comparison presented here $[19,20]$. A random intercept and a random effect for time were included in all analyses to correct for repeated measurement of the outcome. In a first analysis, we included only time the change in position of the head. In a second analysis, we also included et $\mathrm{O}_{2}$ and etCO $\mathrm{C}_{2}$ at baseline (i.e., the measurement of these values just prior to the change of head position) as potential confounders, as etCO $\mathrm{CO}_{2}$ and etO influence the cerebral tissue oxygenation index [20,21]. All analyses of the left and right sides of the brain were performed separately for each side. Results from the analyses will be reported as differences due to hyperextension. Based on the mixed model, we also estimated the mean cerebral blood oxygenation just before the start of the procedure and for the first 10 min during the procedure. These means were reported in Fig. 4.

\section{Results}

\section{Characteristics}

A total of 34 children who underwent cleft lip/palate surgery between May 2015 and May 2017 were included in the final data analysis (Fig. 3). All children were ASA physical status 1 or 2 . The majority of the population was male $(61.8 \%, n=21$, Table 1: Patient characteristics). The mean age at palate surgery was 12.9 months (SD 9.583) and the mean weight was $9.4 \mathrm{~kg}$ (SD 3.0).

From the 34 children, $30(88.2 \%)$ children underwent cleft palate repair and $4(11.8 \%)$ underwent cleft lip and simultaneous hard palate repair with a vomer flap. The mean operation time was $100 \mathrm{~min}$ (SD 28.2).

Of the 34 children, $17.8 \%(n=6)$ were diagnosed with one or more syndromes.

\section{Physiological parameters}

MAP, saturation, heart rate, etCO $\mathrm{CH}_{2}$, etO $\mathrm{O}_{2}$ and temperature were perioperatively collected. Those physiological parameters are listed in Fig. 4. No clinically relevant changes were observed in MAP, saturation, heart rate, etCO $\mathrm{CO}_{2}$, and etO $\mathrm{e}_{2}$.

Table 1. Patient characteristics

\begin{tabular}{ll}
\hline Characteristic & $\begin{array}{l}\text { Patients } \\
n=34(\%)\end{array}$ \\
\hline Gender & $21(62)$ \\
Male & \\
ASA classification & $22(65)$ \\
Class I & $12(35)$ \\
Class II & $12.9(\mathrm{SD} 9.6)$ \\
Mean age surgery (months) & $9.4(\mathrm{SD} 3.0)$ \\
Weight (kg) & \\
Operation type & $30(88)$ \\
Cleft palate repair & $4(12)$ \\
Cleft lip and palate repair & $6(18)$ \\
Syndrome & $2(6)$ \\
22q11 deletion syndrome & $2(6)$ \\
Pierre Robin Sequence & $1(3)$ \\
Kabuki syndrome & $1(3)$ \\
Pierre Robin Sequence + Catel manzke syndrome &
\end{tabular}


Fig. 3 Flow chart of patient inclusion

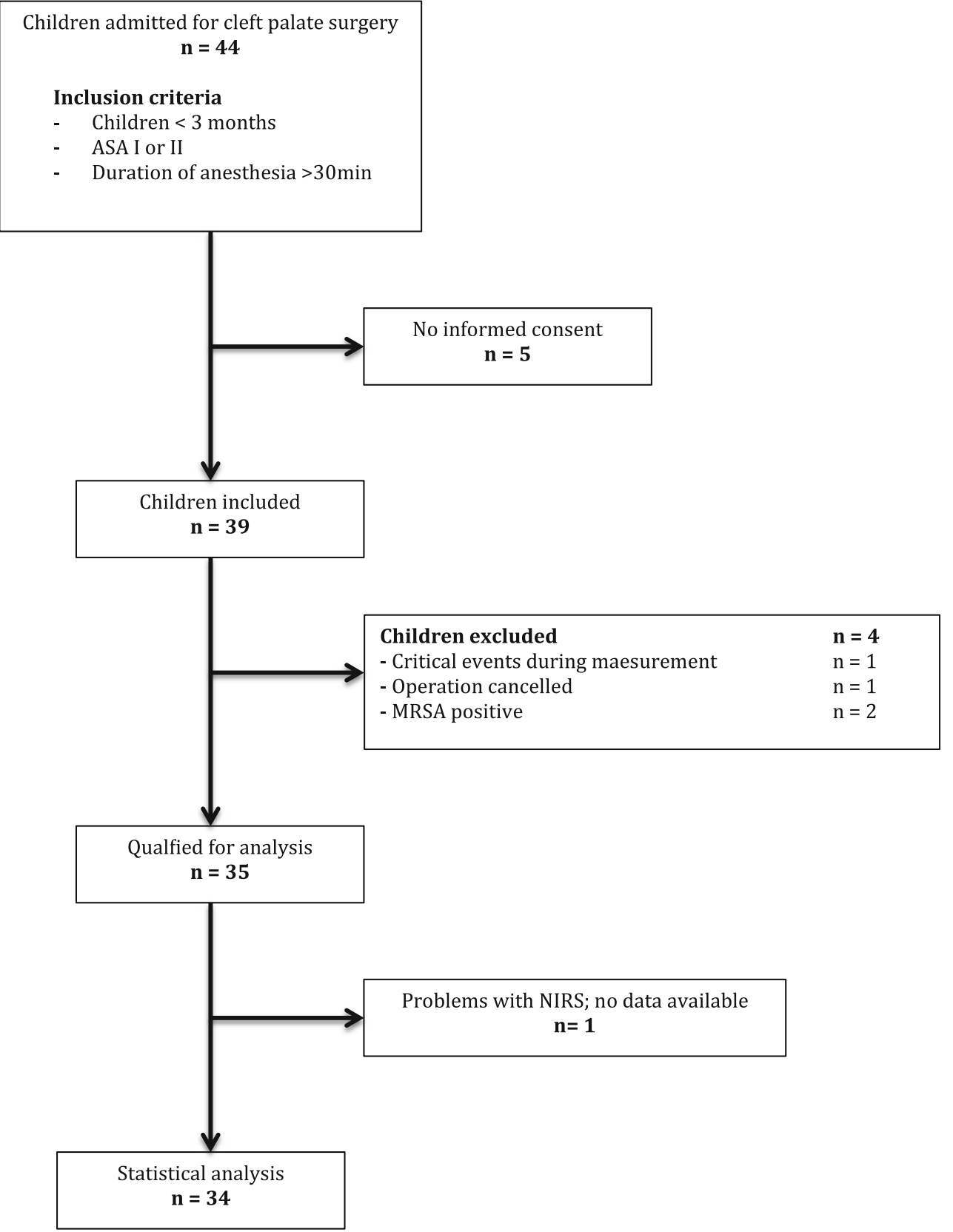

\section{Positioning and head-neck-angle measurement}

By comparing the angles (head/neck angle and head tilt angle) in baseline and extension positions (Fig. 2), the change of head/neck angle and head tilt angle were calculated. The mean head/neck angle and head tilt angle in the baseline were respectively $25^{\circ}$ (range $8^{\circ}-50^{\circ}$ ) and $18^{\circ}\left(\right.$ range $\left.3^{\circ}-40^{\circ}\right)$. The mean head/neck angle and head tilt angle after positioning were respectively, $6^{\circ}\left(22^{\circ}-\right.$ $32^{\circ}$ ) and $39^{\circ}\left(25^{\circ}-56^{\circ}\right)$. This is a mean change of $20^{\circ}$ for the head/neck angle and a mean change of $24^{\circ}$ for the head tilt.

\section{Effect of head position on cerebral blood oxygenation}

To evaluate the impact of Rose position on cerebral blood oxygenation, the cerebral tissue oxygenation index drop at the time of the Rose position was compared with the cerebral tissue oxygenation index drop during baseline and after Rose position. The mean observed cerebral tissue oxygenation index during baseline was left 75 (SD 6.0) and right 75 (SD 7.9). The mean observed cerebral tissue oxygenation index at time of Rose position was 74 (SD 6.3) on the left side and 75 (SD 7.9) on the right side. The mean observed cerebral tissue oxygenation index 5 min after Rose position was 73 (SD 7.6) on 
a Saturation

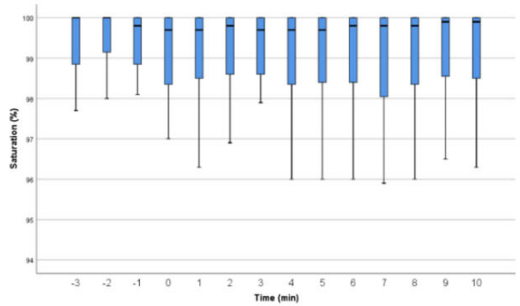

d D. etCO2

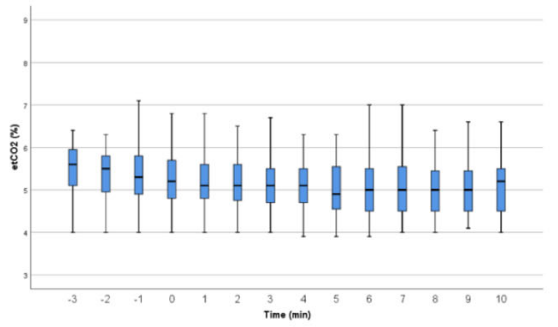

b Heart rate

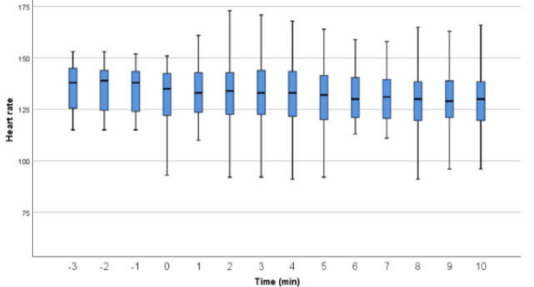

e E. etO2

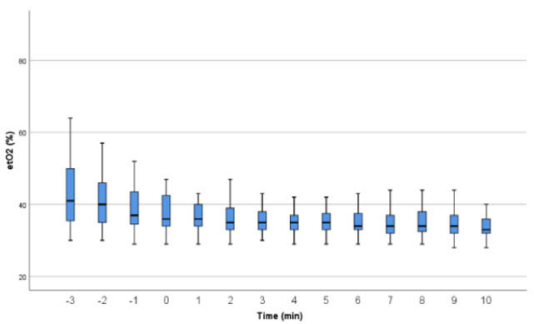

C Temperature

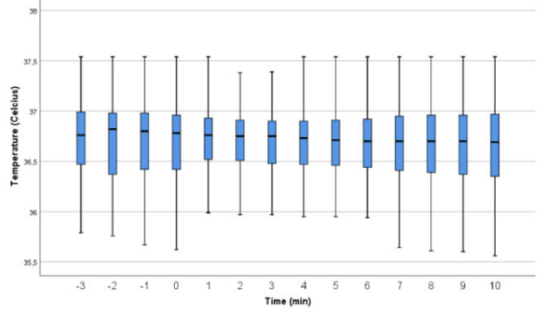

f Cerebral oxygenation (NIRS)

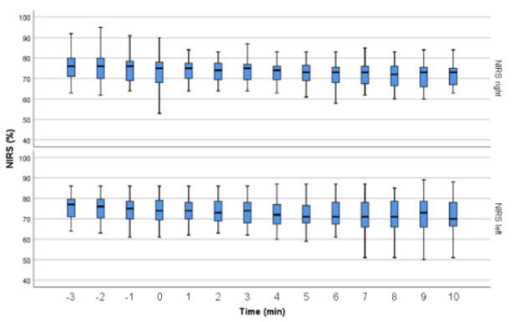

g Mean arterial pressure

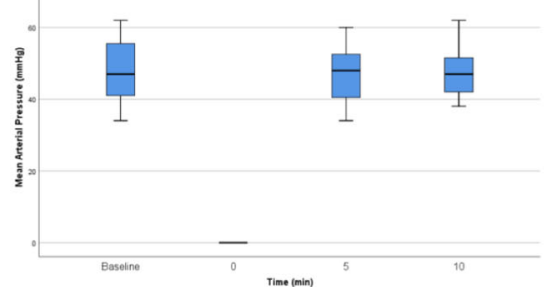

Fig. 4 Physiological parameters. A: Saturation. B: Heart rate. C: Temperature. D: etCO . E: etO $_{2}$. F. Cerebral oxygenation (NIRS). G: Mean arterial pressure. Time $<0$ : Baseline. Time $=0$ : positioning in hyperextension. Time $>0$ : Time after positioning

Fig. 5 Effect of hyperextension of the neck on cerebral blood oxygenation. Estimated values (mixed model analyses) and mean observed values of the NIRS measurements (left and right). Baseline $(\mathrm{T}<0)$, Rose position $(\mathrm{T}=0)$ and the first $10 \mathrm{~min}$ after Rose position $(\mathrm{T}>0)$

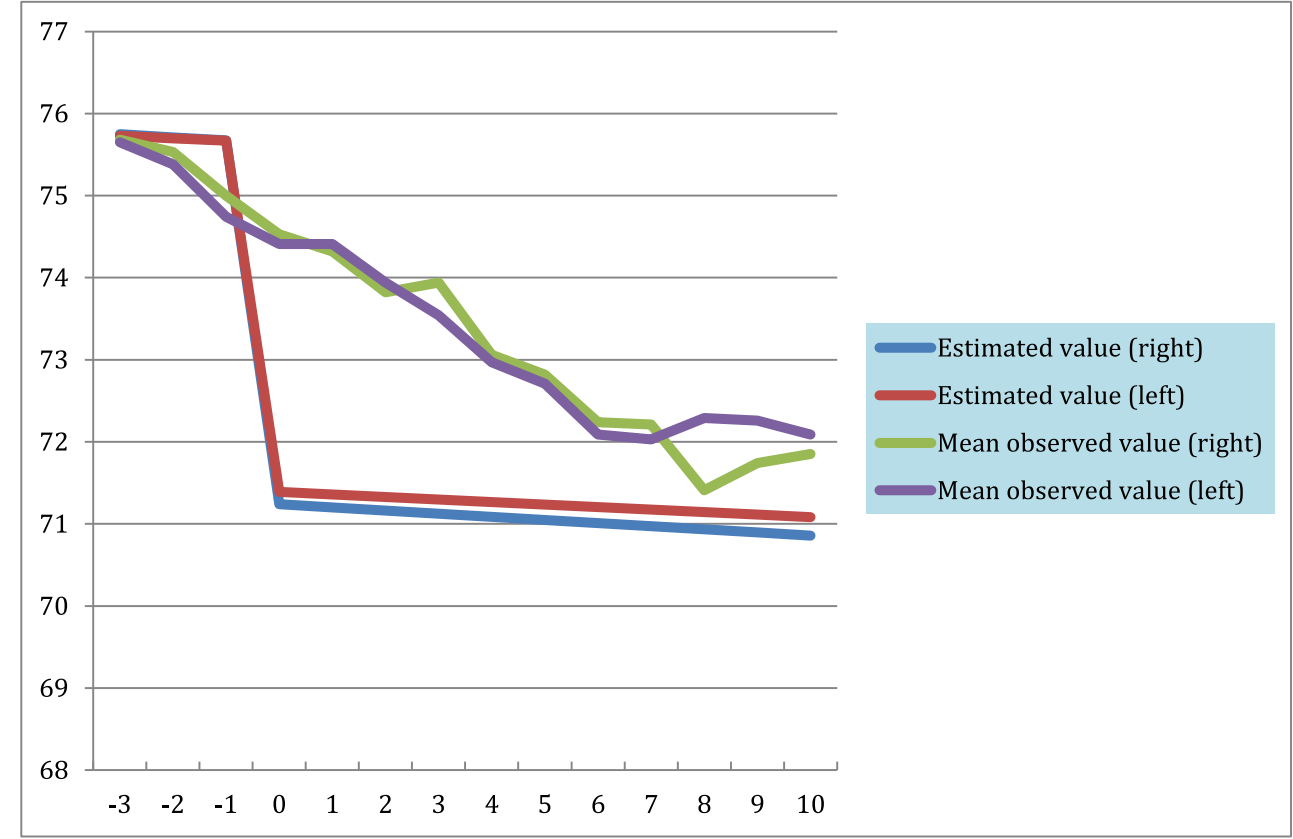


the left side and 73 (SD 7.0) on the right side, and after $10 \mathrm{~min}$ 72 (SD 7.8) on the left side and 72 (SD 8.3) on the right side (Fig. 5).

The mixed model analysis shows a significant drop at the time of Rose position of -4.25 (69-74 95\% CI; $p<0.001$ ) and $-4.39(69-7495 \% \mathrm{CI} ; p<0.001)$, on the left and right sides, respectively. After correction for etO $\mathrm{O}_{2}$ and etCO $\mathrm{CO}_{2}$, the drops were very similar: $-4.25(69-7495 \% \mathrm{CI}$; $(p<0.001)$ for the left side and $-4.39(69-7495 \% \mathrm{CI} ; p<0.001)$ for the right side. This means that, at time of Rose position, there was a significantly greater cerebral tissue oxygenation index drop compared with the cerebral tissue oxygenation index during baseline and after Rose position (during surgery). Figure 5 shows the observed values and estimated values (mixed model analyses) of the cerebral tissue oxygenation index from $3 \mathrm{~min}$ prior to the Rose position to $10 \mathrm{~min}$ after Rose position. A drop in saturation can clearly be observed at $T=0$.

\section{Severe low cerebral saturation events (cerebral tissue oxygenation index $<45$ )}

Severe cerebral desaturation events over a period of at least 3 min were uncommon in this study. In two patients, a cerebral tissue oxygenation index lower than $45 \%$ was observed for longer than $3 \mathrm{~min}$ on the left probe. One patient had one episode of cerebral tissue oxygenation index $<45 \%$ for $6 \mathrm{~min}$ and one patient had four episodes of cerebral tissue oxygenation index $<45 \%$ (1st episode: $6 \mathrm{~min}$, 2nd episode: $7 \mathrm{~min}$, 3rd episode: $7 \mathrm{~min}$, 4th episode: $23 \mathrm{~min}$ ). In both cases, the cerebral tissue oxygenation index on the right probe was $>$ $60 \%$. Although a cerebral tissue oxygenation index of $<45 \%$ could theoretically lead to neurological damage postoperatively, none was observed in our patients. There were no clinical signs of neurological sequelae on post-procedure control of the surgeon. Therefore there was no indication for additional neurological examination.

\section{Discussion}

To our knowledge, this is the first prospective cohort study to investigate the influence of the Rose position on cerebral oxygenation in children.

The mixed model analyses in our study showed a drop in cerebral saturation at the time of Rose position of -4.25 (6974 95\% CI; $p<0.001)$ and -4.39 (69-74 95\% CI; $p<0.001)$ on the left and right sides, respectively. Within infants, various studies have looked at the impact of several head and body positions on cerebral tissue oxygenation, either measured in the midline or bilaterally, and did not find any significant alterations in cerebral tissue oxygenation [23, 24]. In 24 preterm infants, Ancora et al. found that hemodynamic changes after postural variations depend on gestational age [15]. Head rotation in newborns with a gestational age $<26$ weeks produced a reduction in normalized tissue hemoglobin index with stable tissue oxygenation index. No significant changes were detected in newborns with gestational age $>26$ weeks. They concluded that very preterm newborns may be able to compensate a variation in cerebral blood volume and maintain a stable cerebral oxygenation even when positioned in a way that may produce vascular compression.

Liao et al. showed that by turning the head, from midline to lateral in supine positioned preterm infants, leads to a significant decrease in cerebral tissue oxygen saturations [25]. In those studies, the decrease in cerebral tissue oxygenation is mostly like due to cerebral venous blood pooling. On the other hand, other studies found no difference in cerebral tissue oxygenation in sequenced body positioning of infants [23, 24]. In contrast to infants, some significant results in adults were found. Various studies showed a significant decrease of cerebral tissue oxygenation in anesthetized patients when body position was changed from the supine to the sitting position $[14,15,26]$.

No human data exist for the threshold of NIRS for causing brain damage. However, animal studies suggest that a threshold below $60 \%$ is associated with intermediate risk and below $45 \%$ high risk for damage. In the present study, a cerebral tissue oxygenation index event of $45 \%$ lasting greater than 3 min was taken for possible brain damage and poor neurological outcome $[17,18]$. In two patients, a cerebral tissue oxygenation index lower than $45 \%$ was observed for longer than $3 \mathrm{~min}$ on the left probe. In both cases, the cerebral tissue oxygenation index on the right probe was $>60 \%$ during this period. A cerebral tissue oxygenation index $<45 \%$ could induce neurological disturbance postoperatively, but there were no clinical signs of neurological sequelae on post-procedure control of the surgeon.

As we mentioned before this study showed a significant drop in cerebral saturation at the time of Rose position. Baik et al. reported cerebral oxygenation ranges of term infants after birth [27]. At $10 \mathrm{~min}$ after birth, the 50th percentile of cerebral oxygenation index was $75 \%$ (10th-90th percentile range of 62-85). At $15 \mathrm{~min}$ after birth, 50th percentile of cerebral oxygenation index was $73 \%$. One would not imagine that oxygenation became worse at $15 \mathrm{~min}$ after birth compared to $10 \mathrm{~min}$ after birth. Considering that these numbers are nearly identical to the ones reported by the authors, it is not clear whether the drop in cerebral oxygenation after positioning in this study is truly significant physiologically.

The etCO $\mathrm{C}_{2}$ is a reflection/surrogate of partial pressure of carbon dioxide in arterial blood $\left(\mathrm{PaCO}_{2}\right)[21,28]$. The cerebral autoregulation is based on controlling the cerebral blood flow velocity, which is largely influenced by changes in etCO and only minimally by the partial pressure of oxygen in arterial blood $\left(\mathrm{PaO}_{2}\right)[21,22,29]$. In other words, the cerebral autoregulation is assumed to be more dependent on hypo/ 
hypercapnia than on hypoxia. Therefore, in the present study we included etCO $\mathrm{C}_{2}$ at baseline (i.e., the measurement of these values just prior to the change of head position) as a potential confounder.

In some instances, high et $\mathrm{O}_{2}$ during baseline measurements was administered. Prior to intubation, patients were exposed to high content of $\mathrm{FiO}_{2}$, which is known to lead to an overshoot of cerebral tissue oxygenation index values [22]. It would have taken more than $10 \mathrm{~min}$ for the $\mathrm{FiO}_{2}$ to stabilize around $40 \%$. Therefore, the influence of $\mathrm{FiO}_{2}$ could not be ruled out. A longer duration of baseline measurement would have been preferable, but unfortunately, that was not logistically feasible. To make the baseline measurement as reliable as possible, we started the baseline measurement when the $\mathrm{etO}_{2}$ was $<50 \%$.

Several limitations exist in the present study with regard to the measuring technique. $75 \%$ of the vascularization system of the human brain consists of venous circulation and $25 \%$ out of arterial circulation $[30,31]$. This means that the ratio of venous and arterial blood volume has great effect on measured cerebral tissue oxygenation values [21,25]. Sorensen and Greisen investigated the precision of NIRS and found intra individual variations of $5.2 \%$ and inter individual variation of $6.9 \%$ [32]. Furthermore, Hessel et al. compared two types of NIRS devices and found a cerebral oxygenation difference of $20 \%$ [33]. This difference might be due to a difference in calibration of NIRS and manufactures use of specific algorithm [34]. These studies imply that the NIRS devices are not able to take biological variation between patients and possible shifts of blood compartments, before and after postural change, into account. In our study, it was not possible to calibrate the NIRS device and the default calibration settings were used for each patient. In addition, measured cerebral tissue oxygenation might not always be a direct representation of sudden change in body posture or physiology. This is due to the time delay for the oxygenated venous blood to reach its equilibrium [30]. This means that NIRS is a better application for continuous measurement than the measurement of sudden changes in body posture. Transcranial Doppler measurement would be an alternative, because rapid changes in cerebral blood flow could be measured and thus could be a good representative of blood oxygenation by assessing the blood flow velocity changes $[6,14,35]$. Therefore, comparable studies to the present with transcranial Doppler would be a welcome addition.

In addition, the geometry of the child's forehead and its intravascular variability could have influenced our measurement [34]. In some instances, the small forehead made the application of large probes difficult and the possibility exists that sagittal superior sinus or temporal muscles are incorporated in the measurement. Furthermore, intraoperative manipulation of the head by the surgeon and during setup of sterile field could have influenced our measurements.
Sufficient cerebral blood supply is maintained by intracerebral collateral flow even if flow in one or more arteries is compromised and cerebral blood flow is kept almost constant by autoregulation. This physiologic autoregulatory system is a mechanism at arteriolar level, which ensures a constant cerebral blood flow during fluctuations of MAP [36-38]. However, extensive head rotation or extension may induce intraoperative cerebral ischemia if collateral flow is insufficient due to congenital abnormalities. In this study, we did not observe neurological disturbance in any child postoperatively but all patients were classified ASA 1 and 2 .

A potential question is whether or not children with relevant co-morbidity (e.g., neurovascular abnormality, congenital heart defects), that might increase their risk of cerebral hypoperfusion, experience significant reduction in cerebral tissue oxygenation during Rose position, and whether this correlates with clinical sequelae. However, these patients were specifically excluded from this study we think larger study in children with serious morbidity in the future adds nothing further because the influence of the Rose position on cerebral oxygenation is already justified. Another interesting question is whether this variation (drop in cerebral saturation) is a typical part of time under anesthesia for infants or as a result of positioning. In order to understand this, it would be necessary to include a control group in this study.

\section{Conclusion}

This study suggests that Rose position in children who undergo cleft palate surgery leads to a significant decrease in cerebral tissue oxygenation. It is not clear whether the drop in cerebral oxygenation after positioning in this study is truly significant physiologically. Severe cerebral desaturation events during surgery were uncommon and do not seem to be of clinical relevance in ASA 1 and 2 children.

Author contribution B.S.: Study design, Patient recruitment, data collection, writing up of the first draft of the paper.

C.B.: Study design, Patient recruitment, writing up of the first draft of the paper.

M.B.: Study design, Patient recruitment, data collection.

S. A.: Study design, Patient recruitment, data collection.

J.N.: Study design, Patient recruitment, data collection.

A.M.M: Study design, Patient recruitment, Revising paper,

J.G.: Study design, writing up of the first draft of the paper.

\section{Compliance with Ethical Standards}

Conflict of Interest The authors declare that they have no conflict of interest.

Ethical approval All procedures performed in studies involving human participants were in accordance with the ethical standards of the 
institutional and/or national research committee and with the 1964 Helsinki declaration and its later amendments or comparable ethical standards.

Informed consent Informed consent was obtained from all individual participants included in the study.

Open Access This article is distributed under the terms of the Creative Commons Attribution 4.0 International License (http://creativecommons. org/licenses/by/4.0/), which permits unrestricted use, distribution, and reproduction in any medium, provided you give appropriate credit to the original author(s) and the source, provide a link to the Creative Commons license, and indicate if changes were made.

\section{References}

1. Watkins SE, Meyer RE, Strauss RP, Aylsworth AS (Apr 2014) Classification, epidemiology, and genetics of orofacial clefts. Clin Plast Surg 41(2):149-163

2. van den Berg MP, HJJ KRTJ, Bloem JJAM (1994) Schisis, een voortdurend probleem voor de patiënt? Ned Tijdschr Geneeskd 138:1058-1061

3. Phua YS, de Chalain T (Mar 2008) Incidence of oronasal fistulae and velopharyngeal insufficiency after cleft palate repair: an audit of 211 children born between 1990 and 2004. Cleft Palate Craniofac J 45(2): 172-178

4. Losken HW, van Aalst JA, Teotia SS, Dean SB, Hultman S, Uhrich KS (May 2011) Achieving low cleft palate fistula rates: surgical results and techniques. Cleft Palate Craniofac J. 48(3):312-320

5. ScienceDirect. Rose position. Available from: https://www. sciencedirect.com/topics/medicine-and-dentistry/rose-position (accessed 25 september 2018)

6. Fudickar A, Leiendecker J, Kohling A, Hedderich J, Steinfath M, Bein B (Oct 2012) Transcranial Doppler sonography as a potential screening tool for preanaesthetic evaluation: a prospective observational study. Eur J Anaesthesiol 29(10):471-476

7. Hojlund J, Sandmand M, Sonne M et al (2012) Effect of head rotation on cerebral blood velocity in the prone position. Anesthesiol Res Pract 2012:647258

8. Aristokleous N, Seimenis I, Georgiou GC, Nicolaides A, Anayiotos AS (Jun 2015) The effect of head rotation on the geometry and hemodynamics of healthy vertebral arteries. Ann Biomed Eng 43(6):1287-1297

9. Gooding CA, Stimac GK (Feb 1984) Jugular vein obstruction caused by turning of the head. AJR Am J Roentgenol 142(2): 403-406

10. Watson GH (Mar 1974) Effect of head rotation on jugular vein blood flow. Arch Dis Child 49(3):237-239

11. Markus HS (Mar 2004) Cerebral perfusion and stroke. J Neurol Neurosurg Psychiatry 75(3):353-361

12. Favilla CG, Mesquita RC, Mullen M, Durduran T, Lu X, Kim MN, Minkoff DL, Kasner SE, Greenberg JH, Yodh AG, Detre JA (May 2014) Optical bedside monitoring of cerebral blood flow in acute ischemic stroke patients during head-of-bed manipulation. Stroke. 45(5):1269-1274

13. Ancora G, Maranella E, Aceti A et al (2010) Effect of posture on brain hemodynamics in preterm newborns not mechanically ventilated. Neonatology 97(3):212-217

14. Kurihara K, Kikukawa A, Kobayashi A (Jul 2003) Cerebral oxygenation monitor during head-up and -down tilt using near-infrared spatially resolved spectroscopy. Clin Physiol Funct Imaging 23(4): 177-181

15. Gatto R, Hoffman W, Paisansathan C, Mantulin W, Gratton E, Charbel FT (2007) Effect of age on brain oxygenation regulation during changes in position. J Neurosci Methods. Aug 30 164(2): 308-311

16. Yu Y, Zhang K, Zhang L, Zong H, Meng L, Han R Cerebral nearinfrared spectroscopy (NIRS) for perioperative monitoring of brain oxygenation in children and adults. Cochrane Database Syst Rev. Jan 172018 1:CD010947

17. Hou XDH, Teng Y, Shou C, Tang X, Li S et al (2007) Research on the relationship between brain anoxia at different regional oxygen saturations and brain damage using NIRS. Physiol Meas 28:12511265

18. Loepke AW, Golden JA, McCann JC, Kurth CD. Injury pattern of the neonatal brain after hypothermic low-flow cardiopulmonary bypass in a piglet model. Anesth Analg. Aug 2005;101(2):340 348 , table of contents

19. Fitzmaurice GM, Laird NM, Ware JH (2004) Applied longitudinal analysis, 1 st edn. Wiley \& Sons inc.

20. SASmanual: http://support.sas.com/documentation/cdl/en/statug/ 68162/HTML/default/viewer.htm\#statug mixed toc.htm

21. Payne SJ, Mohammad J, Tisdall MM, Tachtsidis I (2011) Effects of arterial blood gas levels on cerebral blood flow and oxygen transport. Biomed Opt Express 2(4):966-979

22. Baerts W, Lemmers PM, van Bel F (2011) Cerebral oxygenation and oxygen extraction in the preterm infant during desaturation: effects of increasing $\mathrm{FiO}(2)$ to assist recovery. Neonatology 99(1): 65-72

23. Bembich S, Oretti C, Travan L, Clarici A, Massaccesi S, Demarini S (2012) Effects of prone and supine position on cerebral blood flow in preterm infants. J Pediatr Jan 160(1):162-164

24. Elser HE, Holditch-Davis D, Levy J, Brandon DH (Oct 2012) The effects of environmental noise and infant position on cerebral oxygenation. Adv Neonatal Care 12(Suppl 5):S18-S27

25. Liao SM, Rao R, Mathur AM (Jun 2015) Head position change is not associated with acute changes in bilateral cerebral oxygenation in stable preterm infants during the first 3 days of life. Am J Perinatol 32(7):645-652

26. Fuchs G, Schwarz G, Kulier A, Litscher G (Apr 2000) The influence of positioning on spectroscopic measurements of brain oxygenation. J Neurosurg Anesthesiol 12(2):75-80

27. Baik N, Urlesberger B, Schwaberger B, Schmölzer GM, Mileder L, Avian A, Pichler G (2015) Reference ranges for cerebral tissue oxygen saturation index in term neonates during immediate neonatal transition after birth. Neonatology 108(4):283-286

28. da Costa CS, Greisen G, Austin T (Nov 2015) Is near-infrared spectroscopy clinically useful in the preterm infant? Arch Dis Child Fetal Neonatal Ed 100(6):F558-F561

29. Geinas JC, Marsden KR, Tzeng YC et al (Aug 2012) Influence of posture on the regulation of cerebral perfusion. Aviat Space Environ Med 83(8):751-757

30. Wong FY, Leung TS, Austin T, Wilkinson M, Meek JH, Wyatt JS, Walker AM (Mar 2008) Impaired autoregulation in preterm infants identified by using spatially resolved spectroscopy. Pediatrics. 121(3):e604-e611

31. Bartocci MSD, Lagercrantz H, Lönnqvist PA (2004) 20 Sevoflurane effect on cerebral haemodynamics during induction of anesthesia in young children assessed by near infrared spectroscopy. Preliminary results. Pediatr Res 56:467-467

32. Sorensen LC, Greisen G (Sep-Oct 2006) Precision of measurement of cerebral tissue oxygenation index using near-infrared spectroscopy in preterm neonates. J Biomed Opt 11(5):054005

33. Hessel TW, Hyttel-Sorensen S, Greisen G (May 2014) Cerebral oxygenation after birth - a comparison of $\operatorname{INVOS}((\mathrm{R}))$ and 
FORE-SIGHT near-infrared spectroscopy oximeters. Acta Paediatr 103(5):488-493

34. Dix LM, van Bel F, Baerts W, Lemmers PM (Nov 2013) Comparing near-infrared spectroscopy devices and their sensors for monitoring regional cerebral oxygen saturation in the neonate. Pediatr Res 74(5):557-563

35. Harms MP, Colier WN, Wieling W, Lenders JW, Secher NH, van Lieshout JJ (Jul 2000) Orthostatic tolerance, cerebral oxygenation, and blood velocity in humans with sympathetic failure. Stroke. 31(7):1608-1614

36. Strandgaard S, Olesen J, Skinhoj E, Lassen NA (1973) Autoregulation of brain circulation in severe arterial hypertension. Br Med J 1(5852):507-510
37. Burton VJ, Gerner G, Cristofalo E et al (2015) A pilot cohort study of cerebral autoregulation and 2-year neurodevelopmental outcomes in neonates with hypoxic-ischemic encephalopathy who received therapeutic hypothermia, BMC Neurol. 15:209

38. Lee JK, Brady KM, Chung SE, Jennings JM, Whitaker EE, Aganga D, Easley RB, Heitmiller K, Jamrogowicz JL, Larson AC, Lee JH, Jordan LC, Hogue CW, Lehmann CU, Bembea MM, Hunt EA, Koehler RC, Shaffner DH (Oct 2014) A pilot study of cerebrovascular reactivity autoregulation after pediatric cardiac arrest. Resuscitation. 85(10):1387-1393

Publisher's note Springer Nature remains neutral with regard to jurisdictional claims in published maps and institutional affiliations. 